\title{
BMJ Open Internet-assisted cognitive behavioural therapy with telephone coaching for anxious Finnish children aged 10-13 years: study protocol for a randomised controlled trial
}

Terhi Luntamo (1) , Tarja Korpilahti-Leino, Terja Ristkari, Sanna Hinkka-Yli-Salomäki, Marjo Kurki, Atte Sinokki, Kaisa Lamminen, Kristiina Saanakorpi, Susanna Saarinen, Marjukka Maunuksela, Saana Sourander, Katja Toivonen, Anna Zadkova, Miia Suilamo, Linda Casagrande, Johanna Palmroth, A Sourander

To cite: Luntamo T, KorpilahtiLeino T, Ristkari T, et al. Internet-assisted cognitive behavioural therapy with telephone coaching for anxious Finnish children aged 10-13 years: study protocol for a randomised controlled trial. BMJ Open 2021;11:e045474. doi:10.1136/ bmjopen-2020-045474

- Prepublication history for this paper is available online. To view these files, please visit the journal online (http://dx.doi org/10.1136/bmjopen-2020045474).

Received 03 October 2020 Accepted 17 May 2021

Check for updates

(c) Author(s) (or their employer(s)) 2021. Re-use permitted under CC BY-NC. No commercial re-use. See rights and permissions. Published by BMJ.

Department of Child Psychiatry, University of Turku and Turku University Hospital; INVEST Research Flagship Center, University of Turku, Finland

\section{ABSTRACT}

Introduction Childhood anxiety is common, causes significant functional impairment and may lead to psychosocial problems by adulthood. Although cognitive behavioural therapy (CBT) is effective for treating anxiety, its availability is limited by the lack of trained CBT therapists and easily accessible local services. To address the challenges in both recognition and treatment, this study combines systematic anxiety screening in the general population with a randomised controlled trial (RCT) on internet-assisted CBT (ICBT) with telephone coaching. Child, family and intervention-related factors are studied as possible predictors or moderators, together with the COVID-19 pandemic.

Methods and analysis The study is an open two-parallel group RCT, stratified by sex, that compares ICBT with telephone coaching to an education control. Children aged 10-13 are screened at yearly school healthcare check-ups using five items from the Screen for Child Anxiety Related Disorders (SCARED) Questionnaire. The families of children who screen positive for anxiety are contacted to assess the family's eligibility for the RCT. The inclusion criteria include scoring at least 22 points in the 41-item SCARED Questionnaire. The primary outcome is the SCARED child and parent reports. The secondary outcomes include the impact of anxiety, quality of life, comorbidity, peer relationships, perceptions of school, parental well-being and service use. Additional measures include demographics and life events, anxiety disorder diagnoses, as well as therapeutic partnerships, the use of the programme and general satisfaction among the intervention group.

Ethics and dissemination The study has been approved by the research ethics board of the Hospital District of South West Finland and local authorities. Participation is voluntary and based on informed consent. The anonymity of the participants will be protected and the results will be published in a scientific journal and disseminated to healthcare professionals and the general public. 
adverse development, decreased readiness for work and marginalisation, causing a further economic burden on society.

Cognitive behavioural therapy (CBT) is an effective treatment for childhood anxiety disorders, ${ }^{45}$ but only a minority of children who need support are referred to appropriate services. ${ }^{6}$ There are several obstacles to getting appropriate treatment, such as a lack of resources, having to travel long distances to appointments and stigma. Alternative ways to deliver easily accessible, low-threshold treatment are needed. The ongoing COVID-19 pandemic has also highlighted the need for socially distanced health provision. Previous randomised controlled trials (RCTs) have found that digitally delivered CBT was superior when compared with a wait list control, ${ }^{7-11}$ treatment as usual $^{1213}$ or digitally delivered non-CBT programmes, ${ }^{14} 15$ and as effective as face-to-face CBT. ${ }^{914}{ }^{16}$ However, most of the earlier studies only included children with diagnosed anxiety disorders, clinical populations and those who were recruited from the general population by advertisements. No previous studies have focused on the efficacy of internet-assisted CBT (ICBT) initiatives, following population-based screening of children with symptoms that indicate high levels of anxiety.

Conducting an intervention study based on systematic symptom screening in the general population has one great advantage. That is avoiding the selection bias that is inherent in studies based on clinical samples or cohorts recruited from advertisements. Systematic symptom screening, combined with an easily accessible treatment programme, creates novel opportunities. These including reaching those children whose symptoms have not been recognised or interpreted properly and families who have not contacted mental health services. This is extremely important when it comes to addressing the unmet needs of children with anxiety. For example, only $18 \%$ of the parents who took part in a Finnish study, and reported that their children, aged 8-9 years, had emotional symptoms, stated that the family had been in contact with a mental health provider. ${ }^{17}$

The primary objective of this RCT is to evaluate the efficacy of an ICBT programme, with additional telephone coaching, for anxious children aged 10-13 years. The children will be recruited following screening for anxiety at routine, annual school health check-ups across selected areas of Finland. This initial screening will be based on five key items drawn from the Screen for Child Anxiety Related Disorders (SCARED) Questionnaire. We believe that this ICBT and telephone initiative will be superior to an education control. In addition, we will study the child, family and intervention-related factors that may mediate or moderate the treatment outcomes. The current global health emergency also provides us with an unprecedented opportunity to examine how the COVID-19 pandemic will affect the feasibility and efficacy of the socially distanced ICBT.
School healthcare screening for anxiety in children aged $10-13$ years * Geographic areas: cities of Tampere, Turku, Espoo, Orivesi and counties of North Karelia and Central Osthrobotnia

* Screen positive: scoring a total of $\geq 3$ or 2 for one item using a 5 -question screening instrument

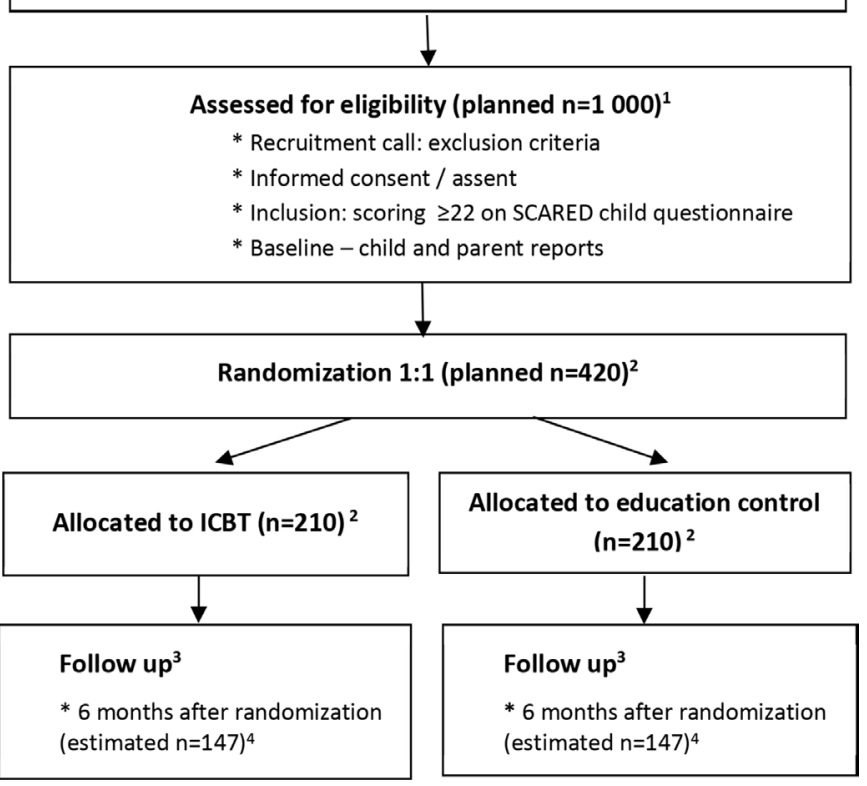

Figure 1 Flow chart of the planned study. ICBT, internetassisted cognitive behavioural therapy; SCARED, Screen for Child Anxiety Related Disorders.

\section{METHODS AND ANALYSIS}

\section{Study type and design}

The study is an open two-parallel group RCT stratified by sex, which compares the ICBT plus telephone coaching to an active comparator, that is, educational control providing psychoeducation on childhood anxiety. Both groups will receive treatment as usual. The education control was considered an ethical choice, as most children with anxiety symptoms get no treatment at all. If treated, the treatment commonly includes a supportive contact with a professional, such as a psychologist or a psychiatric nurse. In more severe cases, when the diagnostic criteria are reached, different forms of psychotherapy or medication may be used. All forms of additional treatments will be controlled for in the analyses. The flow chart for the study is presented in figure 1 .

\section{Screening phase}

The study population consists of the children aged 10-13 years, in grades 4-6, who attend comprehensive schools in the Finnish cities of Turku, Tampere and Orivesi and the counties of North Karelia and Central Osthrobotnia. It also includes children aged 11-13, from grades 5-6, in the city of Espoo. We chose early adolescence for this study, as this developmental phase entails a significant increase in the occurrence of anxiety disorders and symptoms. The screening started in August 2017 in Turku, in January 2018 in North Karelia, in March 2018 in Tampere and Orivesi and in August 2018 in Espoo and Central Osthrobotnia. 
During the annual routine school healthcare check-up, the child's anxiety symptoms are assessed with a short screening instrument that includes altogether five items based on the 41-item SCARED child report. ${ }^{18}$ The school nurse administers the questionnaire to each child. The study group chose one statement from each of the five SCARED subscales: general anxiety (I am nervous), separation anxiety (I get scared if I sleep away from home), panic disorder (when I get frightened, I feel dizzy), school phobia (I am scared to go to school) and social anxiety (I feel nervous when I am going to parties, dances or any place where there will be people that I do not know well). Each item is scored zero for not true or hardly ever true, one for somewhat true or sometimes true and two for very true or often true. The selection was based on a Finnish epidemiological study ( $\mathrm{N}=342$ ) of children aged 11-13 years. ${ }^{19}$ The statements with the highest sensitivity for predicting possible anxiety disorder were chosen, based on the total SCARED Score. Pearson's correlation coefficient between the 5-item screening scale and the 41-item SCARED child report was 0.77 . It was not possible to use the full questionnaire because of time constraints during the school health check-ups.

About 1 week before the check-up, the parents receive information about the study via an internet-based application that school personnel use to communicate with parents. The parents then provide informed consent, so that the study team can contact them and their child's data can be used. Reminders will be sent if the parents do not respond and they will also be given the chance to talk to the study team if they have any queries. They will also be urged to inform the child about the study in advance. Children will provide written, informed assent during the healthcare check-up and receive verbal information on the study from the school nurse. The children have a possibility to ask questions on the study, and the symptoms they report are further discussed with the nurse. The nurses are carefully educated on anxiety and the study before the trial starts, and they have regular contact with the local study nurses to address any questions they may have.

The study team conducts a recruitment call for the families who give permission if the children have a total score of three or more points, or two points for any of the five items. These indicate having a number of symptoms sometimes or one symptom often. They will be informed about the study protocol and offered the chance to have an eligibility assessment.

\section{Exclusion criteria}

The exclusion criteria includes no internet access, insufficient Finnish or Swedish language skills and visual or hearing impairments that hinder the use of the programme. Families will be excluded if the child has an intellectual disability, autism spectrum disorder, suicidal intentions or a severe mental health disorder, such as severe depression or eating disorder. We will also exclude children with ongoing psychotherapy, or therapy due to start within about 6 months. Children who have been on the same dose of the same anxiety medication for 2 months or more will not be excluded, but if their medication has changed in any way in the last 2 months they will not be able to take part. Families who are involved with child protection services with regard to child custody and abuse investigations will also be excluded, as will parents with severe psychiatric or somatic diseases or any other factors that would hinder their active participation.

\section{Inclusion criteria and baseline}

After informed consent and assent, the children fill in the 41-item SCARED report, which has a possible total score of 82, on a secure web site. If they score at least 22 points, their parents proceed to the digital baseline assessment. The cut-off score was selected to be in line with the preventive focus of the study. It was determined based on data of an earlier epidemiological study conducted in our research centre ${ }^{19}$ and the aim is to catch $25 \%$ of the children with the highest anxiety scores. The measures that are used at baseline, during the intervention and at follow-up, have been shown to be reliable in international studies and were translated back and forth according to good research practice.

\section{Sample size}

The sample size and power of the study were calculated with the two-sample t-test and assumed equal variance for the total SCARED Score. With 147 subjects in both treatment groups we expect to detect a mean difference of 3.0 (SD 8.5) between the intervention and education control groups with an $85 \%$ power and using two-sided significance level of 0.05 . This equates to the between-group effect size of Cohen's $d=0.35$, which is considered in general to be fairly moderate, but very common in similar RCT studies on psychotherapy interventions. Allowing for $30 \%$ attrition over time in both groups we will require 210 participants randomised into each group.

\section{Randomisation and blinding}

Two separate randomisation sequences, by sex, are generated with a 1:1 ratio for the intervention versus education control using a computerised random permuted block sequence generator, SAS V.9.4). Concealed block sizes are used to ensure the study staff are blinded. A sequential, double envelope system, labelled and colourcoded according to sex, is used to conceal the individual placements. As each boy or girl enters the study, the next envelope for that sex is selected, their allocated group is recorded and they are advised by email. If two or more children from the same family are participating in the study, all siblings are allocated to the same study group that the first child was placed in. The study statistician creates the randomisation code using only letters ' $\mathrm{A}$ ' and 'B' for the two groups. She stays blinded to the treatment groups until the randomisation expert opens the coding after blinded primary analyses at the end of the study, that is, reveals the treatment groups. The randomisation expert is responsible for the technical randomisation 
Table 1 Study measures

\begin{tabular}{|c|c|c|c|c|}
\hline & Baseline & During the ICBT & After the ICBT & Follow-up (6 months) \\
\hline Demographics & $x$ & & & \\
\hline Life events & $x$ & & & $\mathrm{x}$ \\
\hline \multicolumn{5}{|l|}{ Anxiety } \\
\hline SCARED-C+P*† & $\mathrm{x}$ & & & $\mathrm{x}$ \\
\hline CAIS-C+P† & $x$ & & & $x$ \\
\hline DAWBA-C+P (a) & $\mathrm{x}$ & & & $\mathrm{x}$ \\
\hline \multicolumn{5}{|l|}{ Quality of life } \\
\hline Kid-Kindl-C+P† & $\mathrm{x}$ & & & $\mathrm{x}$ \\
\hline \multicolumn{5}{|l|}{ Comorbidity } \\
\hline $\mathrm{CDI}-\mathrm{C} \dagger$ & $x$ & & & $\mathrm{x}$ \\
\hline SDQ-P† & $x$ & & & $\mathrm{x}$ \\
\hline Relationships with peers and school $\dagger$ & $x$ & & & $x$ \\
\hline \multicolumn{5}{|l|}{ Parental well-being } \\
\hline DASS-21† & $\mathrm{x}$ & & & $\mathrm{x}$ \\
\hline BRS† & $x$ & & & $x$ \\
\hline
\end{tabular}

Alliance

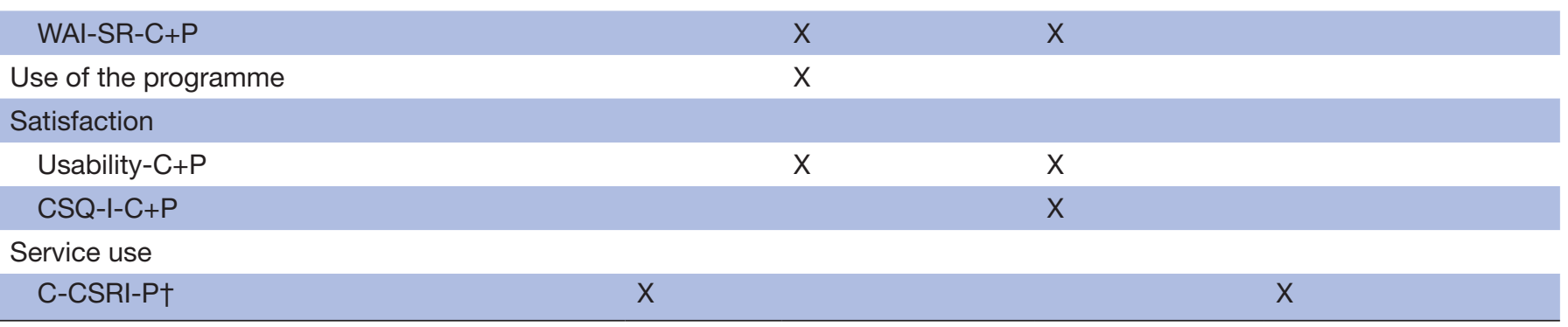

*Primary outcome measure (total scores).

†Secondary outcome measure (for the SCARED subscales only).

‡Only for the ICBT group.

. a, only anxiety; BRS, Brief Resilience Scale; C, child-report; CAIS, Child Anxiety Impact Scale; C-CSRI, Customised Client Service Receipt Inventory; CDI, Child Depression Inventory; CSQ-I, Client Satisfaction Questionnaire; DASS-21, Depression Anxiety and Stress Scale; DAWBA, Development and Well-Being Assessment; ICBT, internet-assisted cognitive behavioural therapy; Kid-KIndl, measuring Healthrelated Quality of Life; P, parent-report; SCARED, Screen for Child Anxiety Related Disorders; SDQ, Strengths and Difficulties Questionnaire; WAI-SR, Working Alliance Inventory-Short Revised.

process and the envelopes. Neither the statistician $(\mathrm{SH}-$ Y-S) nor the randomisation expert (ASi) are directly involved in conduct of the study though they are part of the study team.

\section{Measures}

A summary of the measures used is presented in table 1 .

\section{Primary outcome}

The primary outcome measure is the 41-item SCARED (child and parent report), which screens the child's anxiety symptoms during the last 3 months. ${ }^{18}{ }^{20}$ Each item is scored zero for not true or hardly ever true, one for somewhat true or sometimes true and two for very true or often true. This generates a maximum score of 82 . SCARED has been evaluated by several studies and proven to be a reliable tool for assessing childhood anxiety. ${ }^{21}{ }^{22} \mathrm{In}$ a Finnish study, ${ }^{19}$ the internal consistency was $\alpha=0.92$ for the child report and $\alpha=0.90$ for the parent report. As the concordance between these two reports on anxiety tend to vary from low to moderate, and the use of multiple informants is generally recommended, ${ }^{23}$ SCARED measures are used as separate primary outcomes. The subscales on general anxiety, separation anxiety, panic disorder, school phobia and social anxiety are analysed as secondary outcomes.

\section{Secondary outcomes}

The 27-item Child Anxiety Impact Scale assesses what effect the child's anxiety has on daily life at home, school and with friends. The internal consistency of the total scales and subscales have varied from $\alpha=0.70$ to $0.90 .^{2425}$

The 24-item Revised Children Quality of Life Questionnaire measures health-related quality of life and has six subscales: physical, psychological, self-esteem, family, social life and school. The scores are transformed into a 
$0-100$ scale. Cronbach's alpha coefficients for the scales have ranged from $\alpha=0.63$ to $0.84 .{ }^{26}$

\section{Comorbid symptoms}

The children fill in the 27-item Child Depression Inventory that screens for the child's depressive symptoms $(\alpha=0.840) .^{27}$

The parents fill in the extended 25-item Strengths and Difficulties Questionnaire ${ }^{28}$ to assess the child's symptoms and positive attributes. The questionnaire has five subscales: emotional symptoms, hyperactivity-inattention, conduct problems, peer problems and prosocial behaviour $(\alpha=0.840) .{ }^{29}$ The extended version includes an impact supplement that provides further information about the child's possible problems, such as chronicity, distress, social impairment and burden on others.

\section{Peer relationships and perceptions of school}

Three questions explore the child's experiences of being bullied during the last 6 months: They are asked whether and how often they have been bullied at school, outside the school time, or in the internet, and whether bullying was physical, verbal or ignoring and leaving out on purpose. Additionally, they are asked whether they have told someone about it, such as a parent, a teacher, another adult or a friend. Perceptions of their school include their feelings about whether the teachers care about them, and whether they feel safe and social cohesion at school. The measures were created by the study group.

\section{Parental well-being}

The parents complete the 21-item Depression Anxiety and Stress Scale Short Form (DASS-21) $(\alpha=0.90)^{30}{ }^{31}$ to identify those three issues. Parental resilience is assessed by the six-item Brief Resilience Scale $(\alpha=0.80-0.91){ }^{32}$

\section{Service use}

The Customised Client Service Receipt Inventory Questionnaire for parents ${ }^{33}$ assesses the child's use of school support services and social and healthcare services.

\section{Additional measures Demographics}

The parents answer questions about the child's gender and age, family structure, languages spoken by the family, parental occupation, education and employment status and family income. Summarised demographic and baseline variables will be presented for the two groups.

\section{Life events}

The parents provide information on whether the child has been exposed to parental divorce or separation, unemployment, a significant deterioration in household finances or the death or severe illness of any parents or siblings during the past 6 months.

\section{Anxiety diagnoses}

The Development and Well-Being Assessment (DAWBA), designed to generate psychiatric diagnoses of children aged $2-17,,^{34-36}$ is applied at baseline. The child and parental reports will be used to assess possible child anxiety disorders. The assessment is only administered at follow-up for the intervention group, to keep the number of items reasonable for the control group, due to the concise psychoeducational material they receive. This ensures sufficient participation at follow-up.

Quality of the therapeutic alliance with the coach

Children and their parents both fill in the 12-item Working Alliance Inventory-Short Revised ${ }^{37}$ after ICBT modules three, six and nine.

\section{Use of the programme}

The time each child and parent spend on the website is downloaded using appropriate time-out values, including the percentage of primary screens that the participants visit.

\section{Satisfaction}

Each week, the children and their parents are asked five questions regarding satisfaction and 15 questions about the usability of the programme when it finishes. After completing the ICBT, children and their parents fill in the eight-item Client Satisfaction Questionnaire. ${ }^{38}$ This information will provide data on general satisfaction of the participants, and enable further development of the intervention and the platform.

\section{Register-Based data}

Long-term psychiatric and somatic outcomes are studied with data from the nationwide Finnish registers. These provide admission and discharge dates and primary diagnoses based on International Classification of Diseases ICD-Tenth Revision. The registers cover all specialist inpatient wards and outpatient clinics, primary healthcare, private and prison hospitals and military wards. Reporting is mandatory and the registers are maintained in accordance with national laws. All citizens have a personal identity code, which allows linkages between the register data and data collected at baseline and follow-up. Informed consent for the use of register data is covered by a separate question that stresses that refusing will not prevent families from taking part in the study.

\section{Treating subjects}

\section{Description of the ICBT intervention}

The intervention was developed by the multidisciplinary study group, which consists of child psychiatrists, psychotherapists, clinical psychologists, coaches who deliver the intervention and information technology professionals. It is based on the components that have been most commonly applied in well-established studies on the efficacy of CBT for different anxiety disorders. ${ }^{39}$ The intervention targets both the child and the parents, because parental inclusion may lead to additional benefits, such as higher parental acceptability and long-term maintenance of treatment gains. ${ }^{40}$ The intervention was piloted among a small group $(n=10)$ of children with clinically 


\begin{tabular}{|c|c|}
\hline Theme & Content \\
\hline Introduction & $\begin{array}{l}\text { Presenting the intervention and } \\
\text { tools }\end{array}$ \\
\hline $\begin{array}{l}\text { Theme 1. Learn to know } \\
\text { anxiety }\end{array}$ & $\begin{array}{l}\text { Psychoeducation (anxiety, fears, } \\
\text { cognitive behavioural therapy) }\end{array}$ \\
\hline Theme 2. Deep breathing & $\begin{array}{l}\text { Breathing techniques, practising } \\
\text { exposure }\end{array}$ \\
\hline $\begin{array}{l}\text { Theme } 3 \text {. Encouraging } \\
\text { thinking }\end{array}$ & $\begin{array}{l}\text { How to recognise and change } \\
\text { negative thoughts, parents' } \\
\text { modelling behaviour }\end{array}$ \\
\hline Theme 4. Relaxation & $\begin{array}{l}\text { Learning how to relax, positive } \\
\text { parenting }\end{array}$ \\
\hline Theme 5. Safe place & $\begin{array}{l}\text { Learning to use imaginary } \\
\text { techniques }\end{array}$ \\
\hline Theme 6. Anxiety Ladders & Gradual exposure \\
\hline $\begin{array}{l}\text { Theme } 7 . \text { Learn by } \\
\text { practising }\end{array}$ & Gradual exposure \\
\hline $\begin{array}{l}\text { Theme } 8 . \text { Control your } \\
\text { anxiety }\end{array}$ & $\begin{array}{l}\text { Summary of the child's and the } \\
\text { parents' skills }\end{array}$ \\
\hline Theme 9. Long-term plan & $\begin{array}{l}\text { Maintenance plan, preventing } \\
\text { setbacks }\end{array}$ \\
\hline $\begin{array}{l}\text { Booster phone call after } \\
1 \text { month }\end{array}$ & Follow-up on skill practising \\
\hline
\end{tabular}

diagnosed anxiety, and was further developed based on their feedback. ${ }^{42}$ The feedback from the participants in the pilot study was very good in general, and only minor technical revisions and slight changes to the scripts of the coaches were made.

The treatment comprises nine internet-based modules, which include digital material for the parent and child, and weekly calls from their coach (table 2).

We recommend that participants spend 1 week on each of them. No face-to-face contact is included. The child's material is shorter than the adult content and adapted to their developmental level and reading skills. The telephone calls ideally last about 30-45 min and the coach speaks with the parents and with the child, when a parent is present. The internet material includes text, pictures, educational audio clips and animations, which comprise the most crucial parts of the programme. The child receives their home assignments from the digital platform and then goes back to provide feedback. In addition, two animated video bloggers (figure 2) talk about their situation and progression every week.

The programme starts with an introduction that provides an overview of the intervention, its objectives and tools and motivation and encouragement for the child and the parent. Then an animated character introduces the first week's theme, which is psychoeducation (figure 3).

Weekly themes 2-5 look at anxiety management skills, such as cognitive restructuring and relaxation techniques. The parents also learns parenting skills, such as positive

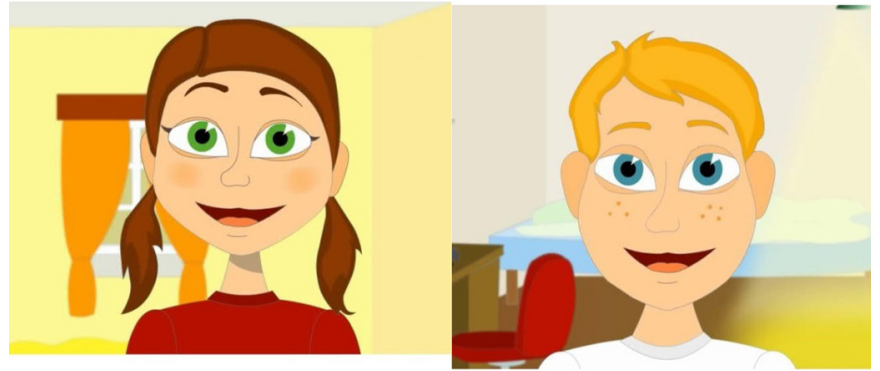

Figure 2 Animated video bloggers, 'Mimosa' has a specific phobia and 'Anton' has a social phobia. They talk about their anxieties and provide peer support for the children using the programme.

modelling, reinforcing the child's brave behaviour and ignoring the child when they complain about their anxiety. Weekly themes 6-8 focus on gradual exposure, by using the most helpful anxiety management skills. To increase the child's motivation and commitment, these focus on the situations that they have chosen (figure 4).

The last theme is about making a long-term plan, to prevent setbacks by sustaining the skills learnt during the intervention. The child is encouraged to share their plan with the coach. They then work together to ensure that the child will know what to do if they have any setbacks. The families receive a booster call approximately 1 month after finishing the treatment and they can use the web-based material for 2 years after they started the programme.

The coaches are healthcare professionals, such as public health and psychiatric nurses with special training to deliver interned-assisted cognitive-behavioural interventions. The training includes a 2-week face-to-face training including theory on anxiety and cognitivebehavioural therapy. Additionally, independent reading and pairwise practicing theme by theme, supplemented with recordings and supervision, is required. The same coaches have earlier delivered an internet-assisted parenttraining programme during an RCT and an implementation phase. ${ }^{4344}$ They receive weekly supervision from a team including, for example, clinical psychologists and

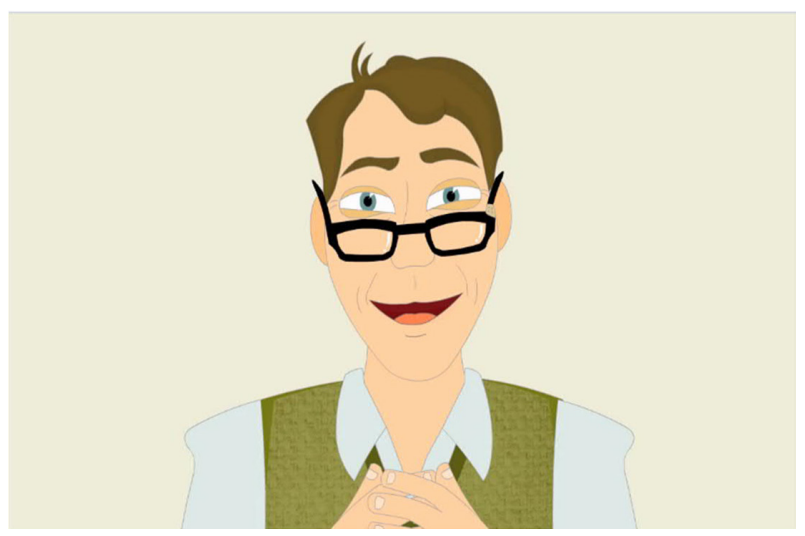

Figure 3 An animated character called Doctor Wunderman provides psychoeducation about anxiety and fears, adapted to the child's developmental stage. 


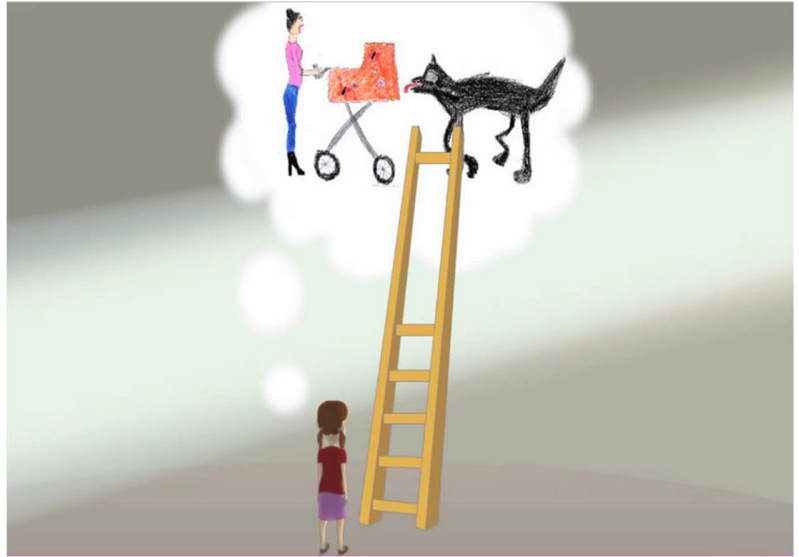

Figure 4 The children and parents work together to plan the ladders for the child's stepwise progress towards the most feared and avoided situations.

psychotherapists. They review the progress made by the child and parents, introduce new skills, help solve problems and provide support and encouragement. The programme content, including the telephone calls, is structured so that all the families get the same treatment. Telephone calls are recorded to ensure the fidelity and quality of the treatment and the participants are informed about this at the start of each call.

\section{Psychoeducational control}

Participants randomised to the education control receive digitally delivered psychoeducation about anxiety. The parents and the children get their own material. The psychoeducational material was developed by the same multidisciplinary group that developed the intervention. After the randomisation, the families who are allocated to the control group, get an automated email with a link directing them to the psychoeducational material on the platform. The content includes the following topics for both the child and the parent: what is normal and abnormal anxiety, how anxiety manifests, anxiety as a part of the child's development, aetiology of excessive anxiety. The child's content also includes material on encouraging thinking, healthy life habits and help seeking. Parental content also includes material on how to encourage, motivate and support the child, show positive example, and take care of your own well-being. The content for the psychoeducational control group is more condensed than for the intervention group, and does not include audio clips, videos, or phone calls.

\section{The digital platform}

The web application was designed and developed with a local third-party software developer. It uses Django, which is an open-source web framework written in Python. It was developed to meet the current needs of the study, but provides the opportunity to extend capabilities to meet future ideas, such as augmented reality and virtual reality technology for practising gradual exposure in a safe environment.
The application can be accessed in different ways by the coaches, parents and children. Parents have access to the child's material and tools, but cannot add any entries. If two parents are involved, both are asked to fill in their own surveys. Coaches can view the participants' profiles, material and tools and the scripts for the telephone sessions.

The application makes sure that the participants go through all the steps in the right order. It automatically sends emails on practical issues, such as the randomisation result and the timing of the follow-up surveys. When the parent and children $\log$ in, the application automatically directs them to any surveys they need to complete.

\section{Data management}

All data gathered via the electronic platform are stored in PostgreSQL database. After collection period is completed, data will be imported to SAS datasets (.sasfiles) for statistical analysing and reporting. Metadata will be stored in spreadsheets (.xlsx-files). We will create a data dictionary which provides guiding principles for dataset and variable construction, as well as study specific information. All source datasets from different data sources will be imported to SAS datasets with programmes that follow guidelines in data dictionary. Code books will be created to document (that is, variable names, labels, types and formats) the contents of SAS datasets. In order to ensure that statistical analyses are conducted on data of acceptable quality, quality control procedures will be implemented.

All baseline questionnaires are filled using electronic platform, which forces participants to fill in all required fields. Platform does not allow selecting multiple choices in likert-type questions. In follow-up phase, participants are given an option to fill in the questionnaires using the electronic platform or paper version. Paper versions are manually digitalised using Microsoft Access. To ensure the consistency of data layout of Access templates, they are made similar as the paper questionnaire. Personnel digitalising paper questionnaires follow predefined guidelines on how to handle unclear answers (ie, multiple answers selected, selection made between two answers etc). All collected survey data are stored on the fileservers of University of Turku. Files are secured by automatic daily backups. Backups are kept for 26 weeks. Data are stored on fileservers with limited access. Only appointed researchers, statisticians and data manager are given access to the data.

\section{Statistics}

All demographic and baseline variables will be presented with summary statistics for intervention and education control groups separately. Frequencies and percentages will be calculated for categorical variables. Means, SD, minimum and maximum values will be calculated for continuous variables. Pearson's $\chi^{2}$ test or Fisher's exact test will be conducted to explore differences in categorical variables at baseline between the children and parents in the intervention and in the education control. Student's 
t-tests will be used to explore differences in continuous variables between the groups at baseline.

The primary outcome measure is the total score of the 41-item SCARED child and parent report. These will be collected at the baseline prior to randomisation ('baseline') and 6 months after randomisation ('follow-up'). We will analyse the SCARED total scores at the follow-up with PROC MIXED in SAS using linear mixed models, adjusting for baseline SCARED total score and having the stratifying factor sex as a covariates. In addition, changes from baseline to follow-up SCARED total score within each treatment group will be analysed with linear mixed models having the stratifying factor sex and baseline as covariates. All analyses will be done separately for children and parents and we will use all available data according to the intention-to-treat principle. The participating children/parents will be included as a random effect in order to generalise the results beyond our study sample, if feasible. As the two primary outcomes are both single measurements, that is, the SCARED total scores for children and for parents, there will be no need for adjustment of $p$ values due to multiple tests. The secondary outcome measures will be analysed using the same modelling approach as for the primary outcomes measures.

We will conduct a number of subgroup analyses including stratified analyses based on (i) the use of 31 points in SCARED total scores in children as a cut-off point, ${ }^{45}$ (ii) the possibility of children's anxiety disorders using DAWBA, (iii) parental DASS-21 scores over the mean in the study population, (iv) completing the 6-month follow-up measurements before or after the worldwide COVID-19 pandemic, (v) completing the 6-month follow-up measurements less than 3 months after finishing the intervention and (vi) adherence in the intervention. In case there is a large number of missing observations at 6 months, we will undertake sensitivity analyses including repeating of the primary SCARED total scores analysis, substituting alternative ranges of values for the 6-month measurement. The purpose is to assess the robustness of our estimates in both intervention and education control groups. A two-sided $\mathrm{p}$ value less than 0.05 will be considered statistically significant. PROC MIXED in SAS (V.9.4) will be used in all statistical analyses.

\section{Patient and public involvement}

The screening process was developed in collaboration with the school healthcare authorities and nurses. The platform, intervention and measures were tested in a small pilot study ${ }^{42}$ of 10 children with clinically diagnosed anxiety. Their families were interviewed and the platform, ICBT and measures were further adapted based on their experiences. The web application that is used to deliver the intervention is constantly being developed.

\section{Ethics and dissemination}

The study has been registered in ClinicalTrials.gov and approved by the research ethics board of the Hospital
District of South West Finland (ETMK:67/1801/2017, approved on 20 June 2017). The relevant bodies have been informed of all the important protocol modifications that have occurred after the original registration and approval. The local authorities in charge of school healthcare have given their permission. Best practice guidelines for conducing RCTs are being followed in accordance with the Recommendations for Interventional Trials. Taking part is voluntary and participants can stop at any time. Children and parents can contact the study team if they have any questions. The internet traffic between the participant and the website is protected. The website is hosted on a secure server, maintained by the University of Turku IT Services in Finland. Data linkage and analysis of data will be undertaken within the host institution and all data will be held, and transferred, securely. Our data management follows the findable, accessible, interoperable and reusable principles ${ }^{46}$ and includes detailed information on data description, storage and the decisions on archiving and preservation after the study ends.

This trial has minimal risk. Similar remote interventions have produced good results in other countries, with no significant adverse events, and a data monitoring committee is not needed. The ICBT comprises the same components as a face-to-face CBT, which is the prioritised evidence-based treatment for anxiety disorders. The exclusion criteria include situations and conditions that could make it difficult to participate or induce adverse effects. Any possible adverse events are handled within the weekly phone calls with the coach, and the participants may as well contact the study personnel any time. The coaches get intensive training and regular supervision from two CBT therapists and can consult a specialist in child psychiatry at any time. If the participant needs child psychiatric care, a referral can be made to free local public services. All participants, regardless of their study group, are entitled to use any other services. Staff are trained to identify and report any suspicion of abuse and neglect according to local legal requirements. The data on why people discontinue the ICBT is collected during the trial and will be reported.

The funders have played no role in the planning of the study. The Research Centre for Child Psychiatry at the University of Turku initiated, planned and is managing the study. The anonymised results will be published in a scientific journal and disseminated to healthcare professionals and the general public. The participants of the present study will also be offered a possibility to answer similar follow-up surveys 1 and 2 years after the randomization. The study participants will not receive any payments, but they will each be sent a movie ticket at the time of the follow-up to thank them for the time they spent participating in the study.

Acknowledgements This work was supported by the INVEST Research Flagship, and PSYCOHORTS consortium. (We would like to thank all the investigators and participants for their helpful comments). 
Contributors All authors contributed to the planning of all parts of the study. TL, SH-Y-S and ASo had the main responsibility for the concept of the study and study design, TK-L and TR for the recruitment and the intervention, ASi for data management and developing the platform, SH-Y-S for statistical matters, and TL, TK-L, TR, MK, KL, KS and SSa for planning the practices of the study. MM, SSo, KT, AZ, MS, LC and PJ contributed to the planning of the recruitment and intervention. TK-L, TR and TL drafted the treatment part of the manuscript, SH-Y-S statistical issues, ASi data management, and TL the other parts of the manuscript. ASo supervised the project. All authors took part in critically revising the manuscript and approved the final version.

Funding This work was funded by the Academy of Finland: Flagship Programme (decision number: 320162 ) and APEX consortium (Awareness, Prevention and Early Interventions, decision number: 303581)

Competing interests None declared.

Patient and public involvement Patients and/or the public were involved in the design, or conduct, or reporting, or dissemination plans of this research. Refer to the Methods and analysis section for further details.

\section{Patient consent for publication Not required.}

Provenance and peer review Not commissioned; externally peer reviewed.

Open access This is an open access article distributed in accordance with the Creative Commons Attribution Non Commercial (CC BY-NC 4.0) license, which permits others to distribute, remix, adapt, build upon this work non-commercially, and license their derivative works on different terms, provided the original work is properly cited, appropriate credit is given, any changes made indicated, and the use is non-commercial. See: http://creativecommons.org/licenses/by-nc/4.0/.

\section{ORCID iD}

Terhi Luntamo http://orcid.org/0000-0003-1448-0503

\section{REFERENCES}

1 Beesdo K, Knappe S, Pine DS. Anxiety and anxiety disorders in children and adolescents: developmental issues and implications for DSM-V. Psychiatr Clin North Am 2009;32:483-524.

2 Silverman WK, Treffers PDA, eds. Cambridge child and adolescent psychiatry. Anxiety disorders in children and adolescents: Research, assessment and intervention. Cambridge University Press, 2001.

3 Pine D, Klein R. Anxiety disorders. in Rutter's child and adolescent psychiatry 628-67. Oxford, UK: Blackwell Publishing Ltd, 2008.

4 Barrett PM, Duffy AL, Dadds MR, et al. Cognitive-Behavioral treatment of anxiety disorders in children: long-term (6-year) followup. J Consult Clin Psychol 2001;69:135-41.

5 Kendall PC, Flannery-Schroeder E, Panichelli-Mindel SM, et al. Therapy for youths with anxiety disorders: a second randomized clinical trial. J Consult Clin Psychol 1997;65:366-80.

6 Sourander A, Lempinen L, Brunstein Klomek A. Changes in mental health, bullying behavior, and service use among eight-year-old children over 24 years. J Am Acad Child Adolesc Psychiatry 2016;55:717-25

7 Infantino A, Donovan CL, March S. A randomized controlled trial of an audio-based treatment program for child anxiety disorders. Behav Res Ther 2016;79:35-45.

8 March S, Spence SH, Donovan CL. The efficacy of an Internet-based cognitive-behavioral therapy intervention for child anxiety disorders. $J$ Pediatr Psychol 2009;34:474-87.

9 Spence $\mathrm{SH}$, Donovan $\mathrm{CL}$, March S, et al. A randomized controlled trial of online versus clinic-based CBT for adolescent anxiety. $J$ Consult Clin Psychol 2011;79:629-42.

10 Stallard P, Richardson T, Velleman S, et al. Computerized CBT (think, feel, do) for depression and anxiety in children and adolescents: outcomes and feedback from a pilot randomized controlled trial. Behav Cogn Psychother 2011;39:273-84.

11 Vigerland S, Ljótsson B, Thulin U, et al. Internet-Delivered cognitive behavioural therapy for children with anxiety disorders: a randomised controlled trial. Behav Res Ther 2016;76:47-56.

12 McGrath PJ, Lingley-Pottie P, Thurston C, et al. Telephone-based mental health interventions for child disruptive behavior or anxiety disorders: randomized trials and overall analysis. J Am Acad Child Adolesc Psychiatry 2011;50:1162-72.

13 Storch EA, Salloum A, King MA, et al. A randomized controlled trial in community mental health centers of computer-assisted cognitive behavioral therapy versus treatment as usual for children with anxiety. Depress Anxiety 2015;32:843-52.
14 Khanna MS, Kendall PC. Computer-Assisted cognitive behavioral therapy for child anxiety: results of a randomized clinical trial. $J$ Consult Clin Psychol 2010;78:737-45.

15 Jolstedt M, Wahlund T, Lenhard F, et al. Efficacy and costeffectiveness of therapist-guided Internet cognitive behavioural therapy for paediatric anxiety disorders: a single-centre, singleblind, randomised controlled trial. Lancet Child Adolesc Health 2018;2:792-801.

16 Schoneveld EA, Lichtwarck-Aschoff A, Granic I. Preventing childhood anxiety disorders: is an applied game as effective as a cognitive behavioral Therapy-Based program? Prev Sci 2018;19:220-32.

17 Lempinen L, Luntamo T, Sourander A. Changes in mental health service use among 8-year-old children: a 24-year time-trend study. Eur Child Adolesc Psychiatry 2019;28:521-30.

18 Birmaher B, Khetarpal S, Brent D, et al. The screen for child anxiety related emotional disorders (scared): scale construction and psychometric characteristics. J Am Acad Child Adolesc Psychiatry 1997;36:545-53.

19 Kaajalaakso K, Lempinen L, Ristkari T, et al. Psychometric properties of the screen for child anxiety related emotional disorders (scared) among elementary school children in Finland. Scand $J$ Psychol 2021;62:34-40.

20 Birmaher B, Brent DA, Chiappetta L, et al. Psychometric properties of the screen for child anxiety related emotional disorders (scared): a replication study. J Am Acad Child Adolesc Psychiatry 1999;38:1230-6.

21 Hale WW, Crocetti E, Raaijmakers QAW, et al. A meta-analysis of the cross-cultural psychometric properties of the screen for child anxiety related emotional disorders (scared). J Child Psychol Psychiatry 2011:52:80-90.

22 Runyon K, Chesnut SR, Burley H. Screening for childhood anxiety: a meta-analysis of the screen for child anxiety related emotional disorders. J Affect Disord 2018;240:220-9.

23 Achenbach TM, Ivanova MY, Rescorla LA. Empirically based assessment and taxonomy of psychopathology for ages 11/2-90+ years: developmental, multi-informant, and multicultural findings. Compr Psychiatry 2017;79:4-18.

24 Langley AK, Bergman RL, McCracken J, et al. Impairment in childhood anxiety disorders: preliminary examination of the child anxiety impact scale-parent version. J Child Adolesc Psychopharmacol 2004;14:105-14.

25 Langley AK, Falk A, Peris T, et al. The child anxiety impact scale: examining parent- and child-reported impairment in child anxiety disorders. J Clin Child Adolesc Psychol 2014;43:579-91.

26 Ravens-Sieberer U, Bullinger M. Assessing health-related quality of life in chronically ill children with the German KINDL: first psychometric and content analytical results. Qual Life Res 1998:7:399-407.

27 Sun S, Wang S. The Children's Depression Inventory in Worldwide Child Development Research: A Reliability Generalization Study. J Child Fam Stud 2015;24:2352-63.

28 Goodman R. The extended version of the strengths and difficulties questionnaire as a guide to child psychiatric caseness and consequent burden. J Child Psychol Psychiatry 1999;40:791-9.

29 Koskelainen M, Sourander A, Kaljonen A. The strengths and difficulties questionnaire among Finnish school-aged children and adolescents. Eur Child Adolesc Psychiatry 2000;9:277-84.

30 Antony MM, Bieling PJ, Cox BJ, et al. Psychometric properties of the 42-item and 21-item versions of the depression anxiety stress scales in clinical groups and a community sample. Psychol Assess 1998; 10:176-81.

31 Fossum S, Cunningham C, Ristkari T, et al. Does parental mental health moderate the effect of a telephone and internet-assisted remote parent training for disruptive 4-year-old children? Scand $J$ Psychol 2018;59:273-80.

32 Smith BW, Dalen J, Wiggins K, et al. The brief resilience scale: assessing the ability to bounce back. Int J Behav Med 2008;15:194-200.

33 Beecham J, Knapp M. Costing psychiatric interventions. personal social services research unit, University of Kent at Canterbury 1999;1536:1-33.

34 Aebi M, Kuhn C, Metzke CW, et al. The use of the development and well-being assessment (DAWBA) in clinical practice: a randomized trial. Eur Child Adolesc Psychiatry 2012;21:559-67.

35 Goodman R, Ford T, Richards H, et al. The development and wellbeing assessment: description and initial validation of an integrated assessment of child and adolescent psychopathology. J Child Psychol Psychiatry 2000;41:645-55.

36 Development and well-being assessment, 2017. Available: https:// youthinmind.com/products-and-services/dawba/ [Accessed 1 Feb]. 
37 Munder T, Wilmers F, Leonhart R, et al. Working alliance InventoryShort revised (WAI-SR): psychometric properties in outpatients and inpatients. Clin Psychol Psychother 2010;17:231-9.

38 Attkisson CC, Zwick R. The client satisfaction questionnaire. psychometric properties and correlations with service utilization and psychotherapy outcome. Eval Program Plann 1982;5:233-7.

39 Banneyer KN, Bonin L, Price K, et al. Cognitive behavioral therapy for childhood anxiety disorders: a review of recent advances. Curr Psychiatry Rep 2018;20:65.

40 Brendel KE, Maynard BR. Child-parent interventions for childhood anxiety disorders: a systematic review and meta-analysis. Res Soc Work Pract 2013;24:287-95.

41 Manassis K, Lee TC, Bennett K, et al. Types of parental involvement in CBT with anxious youth: a preliminary meta-analysis. $J$ Consult Clin Psychol 2014;82:1163-72.
42 Korpilahti-Leino T. Lasten ahdistuneisuushäiriöiden internetavusteisen hoitomallin kehittäminen JA käytön arviointi. pro gradu-tutkielma. Turun yliopisto. Yhteiskuntatieteellinen tiedekunta. Psykologian JA logopedian laitos. Psykologian oppiaine, 2018.

43 Ristkari T, Kurki M, Suominen A, et al. Web-Based parent training intervention with telephone coaching for disruptive behavior in 4-year-old children in real-world practice: implementation study. $J$ Med Internet Res 2019;21:e11446.

44 Sourander A, McGrath PJ, Ristkari T, et al. Internet-Assisted parent training intervention for disruptive behavior in 4-year-old children: a randomized clinical trial. JAMA Psychiatry 2016;73:378-87.

45 Screen for Child Anxiety Related Disorders (SCARED)CHILD Version, 2017. Available: https://www.midss.org/sites/default/files/ scaredchild1.pdf [Accessed 1 Feb].

46 European Commission, DG Research \& Innovation. Guidelines on fair data management in horizon 2020, 2020. 